International Journal of Agriculture, Environment and Bioresearch

Vol. 4, No. 06; 2019

ISSN: $2456-8643$

\title{
NUTRIENT QUALITY AND ASSOCIATED SPOILAGE FUNGI OF ENGLISH PEAR (Pyruscommunis L)
}

\author{
Chuku E. C., Agbagwa, S.s And Worlu, C. \\ Department Of Plant Science And Biotechnology, Rivers State University, Port Harcourt \\ http://doi.org/10.35410/IJAEB.2019.4483
}

\begin{abstract}
Studies on the nutrient quality and associated spoilage fungi of English pear (Pyruscommunis) were carried out in the Department of Plant Science and Biotechnology Rivers University, Port Harcourt. Healthy and spoilt samples of $\mathrm{P}$. cummunis were purchased from the fruit garden market in D. Line, Port Harcourt and used for the study. Results of Proximate analysis revealed the presence of moisture, ash, lipid, carbohydrate, fiber and protein. It was also observed that all the parameters assessed were higher for the spoilt samples except for moisture $(87.51 \pm 0.001)$ and carbohydrate $(10.02 \pm 0.002)$ which were higher in healthy fruit samples. The mineral contents indicated higher values for all parameters (calcium, phosphorus, potassium, iron, sodium and magnesium) in the healthy samples. However, vitamins A, C, and thiamine were available in higher quantities in healthy fruit samples with equal values recorded for niacin $(0.5 \pm$ 0.003 ) for both healthy and spoilt samples. Anti-nutrient and phytochemical investigations revealed phytate, oxalate, saponin, tannin, carotenoid, polyphynol, flavonoid and lignin to be available in appreciable amounts. Nevertheless, two spoilage fungi viz: Aspergillusflavus and A. niger were isolated fromfrom spoilt fruit samples and implicated to cause spoilage as they both proved pathogenic when inoculated into healthy samples of P. communis. Higher percentage incidence $(95 \%)$ was recorded for A. flavus whileA. niger had 5\%.
\end{abstract}

Keywords: Pyruscommunis, nutrient quality, spoilage fungi.

\section{INTRODUCTION}

Pyruscommunis commonly known as English pear is an important member of the Rosaceae family and often cherished for its unique taste (Dzhangalievet al., 2003). The plant holds its origin and distribution in Europe with other sub species such as P. communissubsp. Gharbiana (T.) Maire and P. communis subsp. Marmorensis (Trab.) Maire being reported in Algeria and Morocco (Silva et al., 2014; USDA, 2012).

The tree is said to be deciduous, possessing alternatively arranged simple ovate leaves. Flowers are borne terminally and represent a corymbose inflorescence while fruits are pear shaped containing black seed (Orwaet al., 2009; AOSA 1993). P. communis has a wide range of uses both in the medicinal and industrial sector. More so, its fruit has a wide range of consumption including in the form of juice and is peculiar for its nutritional quality (Gonsalves, 2002; Xieet al., 2007). 
Extensive studies on the nutritional composition of the seed, pulp and peel of $P$. communis fruit were carried out by Mohammed et al., (2010). They revealed the presence of several proximate and mineral constituents such as moisture, lipid, carbohydrate, fibre, protein, phosphorus, magnesium, potassium, sodium and calcium. Furthermore, they implicated many other amino acids and anti-nutritional components in the seed and pulp of $P$. communis. Their study was supported by the report of Hussainet al., (2015) as they indicated the availability of these nutritional components in $P$. communis.

In addition, $P$. communis is a good source of other essential components such as vitamins (A, C, $\mathrm{E}, \mathrm{K}, \mathrm{B} 12, \mathrm{~B} 3$ and B5), phytochemicals (flavonoids, tannin, anthocyanin, alkaloids, triterpenes and oxalate) and other anti-nutritional parametres (Li et al., 2012; Rychilnska\&Gudej, 2003; Milind\&Arzoo, 2016; Yim\& Nam, 2016).

The report of Xieet al., (2007) also showed that the juice made from P. communis is a good source of proximate, mineral and vitamin. More so, literatures have shown the relevance of these nutritional components for healthy living (Vadivel\&Janardhanam, 2015; Senseret al., 1999).

Nevertheless, this wonderful fruit is faced with the challenge of spoilage as they are prone to attack by microorganisms including fungi (Parveenet al., 2016; Joubert\& Doty, 2018).

Muscat et al., (2017) implicated several fungal organisms to be responsible for the deterioration and spoilage $P$. communis fruit and they are viz: Cladosporiumramotenellum, Alternariaarborescens, Penicilliumlanosum, P. expansum and Aspergillussydowii.

Wennekeret al., (2017) also reported Fibulorhizoctoniapsychrophila to be the spoilage agent of the pear fruit causing lenticel spot. Pyrigemmulaaurantiaca was also implicated as aprevalent organism of grapevine trees including P. communis (Magyar et al., 2011).

Thus, this research was carried out to profile the nutritional quality and associated fungi of $P$. communis sold in Port Harcourt metropolis.

\section{MATERIALS AND METHODS}

\section{Sample Collection}

Samples of healthy fruits of $P$. communis and partially rotted fruits were bought from the Fruit Garden Market at D. Line Diobu Port Harcourt and brought to the Department of Plant Science and Biotechnology and sent to the Plant Pathology Laboratory for further studies.

\section{Mycological studies}

\section{Preparation of mycological medium}

Sterilization of conical flask, slides, Petri dishes and all the equipment needed for the experiment was carried out in the laboratory. The glass wares were sterilized in the oven at $120^{\circ} \mathrm{C}$ for an hour after washing with soap, while other equipment were surface sterilized with $70 \%$ ethanol to reduce microbial contamination (Agrios, 2005). Inoculating loops and scalpels were sterilized by dipping for 20 seconds in $70 \%$ ethanol and heated to red hot. The mycological medium used was 
Sabouraud Dextrose Agar prepared in a conical flask using the standard method. The mouth of the flask was plugged with non-absorbent cotton wool and wrapped with aluminium foil. The conical flask containing the mycological medium was autoclaved at $121^{\circ} \mathrm{C}$ and pressure of $1.1 \mathrm{~kg}$ $\mathrm{cm}-3$ for 15 minutes. The molten agar was allowed to cool to about $40{ }^{\circ} \mathrm{C}$ and dispensed into Petri dishes at $15 \mathrm{mls}$ per plate and allowed to further cool and solidify.

\section{Isolation of fungi from partially rotted Pyruscommunis fruits.}

One gram of samples showing visible signs of spoilage by Moulds was cut from the healthy portions of the fruits up to the points where rot had established and inoculated onto Sabouraud Dextrose Agar in Petri dishes onto which ampicillin was added to hinder the growth of bacteria in triplicate. The inoculated plates were incubated for 5 days at ambient temperature of $25^{\circ} \mathrm{C} \pm$ $3^{\circ}$ C (Baudoni, 1988; Chuku, 2009; Samson et al, 1981). The entire set up was observed for 7 days to ensure full grown organisms. Pure culture of isolates were obtained after a series of isolations.

\section{Identification of fungal organisms from Pyruscommunis}

Microscopic examination of fungal isolates was carried out by the needle mount method (Cheesebrough, 2000). The fungal spores were properly teased apart to ensure proper visibility. The well spread spores were stained with cotton blue in lacto phenol and examined microscopically using both the low and high power objective. The fungi were identified based on their spore and colonial morphology, mycelia structure and other associated structures using the keys of (Samson et al, 1981 and Olds, 1983).

\section{Pathogenicity studies}

Pathogenicity studies was carried out on $P$. communis to check if the fungi isolated from the rotted fruits were capable of causing spoilage on healthy fruits samples. The methods of (Agrios, 2005; Trigiano, 2004) was basically followed. The fungal isolates were introduced into healthy fruits and observed for seven days. The set up was monitored regularly for growth.

\section{Determination of nutrient components of fruits of Pyruscommunis.}

Healthy and spoilt fruit samples of $P$. communis were sent to the Food Science and Technology Laboratory for the determination of nutrient composition. The methods of AOAC, (2005) was used for the analysis.

\section{Determination of percentage incidence}

The percentage incidence of fungal occurrence was determined by the formular stated below (Nnaji and Rao, 2017):

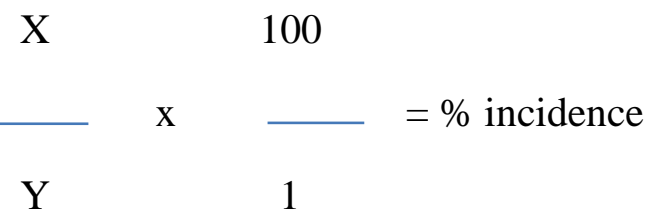


Where:

$\mathrm{X}=$ total number of each organism in a variety

$\mathrm{Y}=$ total number of all identified organism in a variety

\section{RESULTS AND DISCUSSION}

Table 1: Proximate composition of healthy and spoilt fruit of $P$. communis

\begin{tabular}{|lll|}
\hline Parameters & Healthy (\%) & Spoilt (\%) \\
Moisture & $87.51 \pm 0.001$ & $80.4 \pm 0.004$ \\
Ash & $0.14 \pm 0.015$ & $0.25 \pm 0.021$ \\
Lipid & $0.05 \pm 0.004$ & $0.06 \pm 0.003$ \\
Carbohydrate & $10.02 \pm 0.002$ & $8.5 \pm 0.032$ \\
Fibre & $0.05 \pm 0.001$ & $0.15 \pm 0.001$ \\
Protein & $2.22 \pm 0.012$ & $10.63 \pm 0.002$ \\
\hline
\end{tabular}

Table 2: Mineral composition of healthy and spoilt fruit of $\boldsymbol{P}$. communis

\begin{tabular}{|lll|}
\hline Parameters & Healthy $(100 \mathrm{mg} / \mathrm{g})$ & Spoilt $(100 \mathrm{mg} / \mathrm{g})$ \\
Calcium & $12.2 \pm 0.003$ & $10.5 \pm 0.006$ \\
Phosphorus & $10.1 \pm 0.021$ & $8.1 \pm 0.054$ \\
Potassium & $110 \pm 0.023$ & $95 \pm 0.006$ \\
Iron & $4.5 \pm 0.001$ & $4.2 \pm 0.001$ \\
Sodium & $9.5 \pm 0.005$ & $8.4 \pm 0.012$ \\
Magnesium & $8.4 \pm 0.013$ & $4.8 \pm 0.003$ \\
\hline
\end{tabular}


International Journal of Agriculture, Environment and Bioresearch

Vol. 4, No. 06; 2019

ISSN: $2456-8643$

Table 3: Vitamin composition of healthy and spoilt fruit of $\boldsymbol{P}$. communis

\begin{tabular}{|lll|}
\hline Parameters & Healthy $(100 \mathrm{mg} / \mathrm{g})$ & Spoilt $(100 \mathrm{mg} / \mathrm{g})$ \\
Vitamin A & $5.2 \pm 0.013$ & $5.0 \pm 0.042$ \\
Thiamin & $1.2 \pm 0.033$ & $1.0 \pm 0.014$ \\
Naicin & $0.5 \pm 0.003$ & $0.5 \pm 0.023$ \\
Vitamin C & $16.5 \pm 0.021$ & $16.0 \pm 0.001$ \\
\hline
\end{tabular}

Table 4: Anti-nutritional and phytochemical composition of healthy fruit of $P$. communis

\begin{tabular}{|ll|}
\hline Parameters & Healthy $(100 \mathrm{mg} / \mathrm{g})$ \\
Phytate & $0.02 \pm 0.032$ \\
Oxalate & $0.1 \pm 0.010$ \\
Saponin & $0.05 \pm 0.021$ \\
Tannin & $0.01 \pm 0.011$ \\
Carotenoid & $0.52 \pm 0.016$ \\
Polyphynol & $0.04 \pm 0.023$ \\
Flavonoid & $0.35 \pm 0.041$ \\
Lignin & $0.85 \pm 0.001$ \\
\hline
\end{tabular}

Table 5: Fungi isolates and their percentage incidence

Isolates

Percentage incidence $(\%)$

Aspergillusflavus $\quad 95 \pm 0.003$

Aspergillusniger $\quad 5 \pm 0.012$

The result of proximate composition presented in Table 1 . Showed the availability of moisture, ash, lipid, carbohydrate, fiber and protein both in the healthy and spoilt samples of $P$. communis. However, higher values of moisture $(87.51 \pm 0.001)$ and carbohydrate $(10.02 \pm 0.002)$ were 
recorded for the healthy samples while all other parameters were higher in the spoilt sample. The proximate result of this study disagrees with that reported by Mohammad et al., (2015) as they revealed higher values compared to their equivalents in this study. Nevertheless, the moisture contents of the present study were higher than those they reported for the pulp, seed and peel of P. communis. Although it agrees with the $83.1 \pm 2.13$ reported byHussainet al., (2015). Zhang, (2015) reported lower protein value (0.22) and similar value of carbohydrate (10.0) for Pyruspyrifolia juice.

Table 2. Outlined the mineral composition of P. communis and revealed that the healthy fruit had higher contents of calcium, phosphorus, potassium, iron, sodium and magnesium at $12.2 \pm 0.003,10.1 \pm 0.021,110 \pm 0.023,4.5 \pm 0.001,9.5 \pm 0.005$ and $8.4 \pm 0.013$ respectively compared to their equivalents in the spoilt samples. The magnesium value for the healthy sample in this study is in line with the $8.04 \pm 0.52$ reported by Mohammad et al., (2015). However, other mineral values in this study are not consistent with their respective correspondents they reported. In addition, the iron value of this study concurs to the 4.32 \pm 0.31 reported by Yim\& Nam, (2015) and they also reported same mineral parameters but at higher concentrations.

Furthermore, the vitamin composition of $P$. communis represented in Table 3. Implicated higher values for Vitamins A, C and thiamine in the healthy samples than those recorded for the spoilt samples. However, equal values for niacin were recorded for both healthy and spoilt samples for P. communis. The report of Milind\&Arzoo, (2016) agrees with the vitamin parameters profiled in this study. Chen et al., (2005) reported lower values of Vitamin C and thiamine in the juice content of Pyrus fruit.

Anti-nutritional and phytochemical components arrayed in Table 4. revealed several componentssuch asphytate, oxalate, saponin, tannin, carotenoid, polyphynol, flavonoid and lignin to be available in appreciable amounts in P. communis. Hussainet al., (2015) and Mohammed et al., (2015) implicated phytate, oxalate, hydrocyanicglucosides and nitrate to be present in $P$. communis. Occurrence of flavonoid, tannin and alkaloid were also indicated in the research of Sharma et al., (2015).

Proximate, mineral, vitaminand anti-nutritional contents are essential for daily living. They contribute to the supply of amino acid (protein), energy (lipid and carbohydrate), reduce cholesterol level (fiber) and aid in adequate biochemical, physiological and metabolic processes (Ladejiet al., 2004; Pugatenthiet al., 2004). Phytochemicals have been reported by early researcher to possess antimicrobial potential (Kaur \&Arya, 2012).

Two fungi organisms (Aspergillusflavus and A. niger) were isolated from spoilt P. communis (Table 5.) and proved to be pathogenic when inoculated into healthy fruit sample. While $A$. flavus had higher incidence(95\%), A. niger recorded a percentage incidence of 5\%. Earlier studies had shown the susceptible nature of $P$. communis to fungi (Wennekeret al., 2017; Magyar et al., 2011). Moreso, the fungal isolates from this study agrees with Muscat et al., (2017) as they also implicated Aspergillus species to cause spoilage of $P$. communis fruit. The activities of these microorganisms were evident in the unpleasant appearance and foul smell of the spoilt fruits; this in turn affected their marketability. 


\section{CONCLUSION}

Pyruscommunis fruit is endowed with vital nutrients which cut across proximate, mineral, vitamin, anti-nutritional and phytochemical divisions. But it is attacked and infected spoilage organisms. Therefore, proper hygienic measures should be adopted when by farmers and vendors. More so, consumers should ensure to wash properly before eating.

\section{REFERENCES}

A.O.A.C., (2005). Official Methods of Analysis of AOAC International. $18^{\text {th }}$ edition. Association of Official Analytical Chemists, Washington, D.C, USA.

Agrios, G. N., (2005). Plant Pathology, $5^{\text {th }}$ edition. Elsevier Academic Press, USA 383-557.

AOSA, (1993). Rules of testing seeds. Journal of Seed Technology, 16(3): 1-113.

Baudoni, A.B.A.M., (1988). Diagnosis of disease and proof of pathogenicity (Koch's Postulate) in Laboratory exercises in Plant Pathology. An instructional kit, Baudoni.

Cheesebrough, M., (2000). District Laboratory Practice in Tropical Countries, Part 2. Cambridge University Press, London. 143- 156.

Chen D. H., Zhang Q. Y. \& Jong H. G. (2005). The processing technique of healh beverage from pear juice and Lentinusedodes polysaccharide. Pack and Machinery, 26: 135-139.

Chuku, E C., (2009). Fungi responsible for the spoilage of Plantain (Musa paradisiaca) at various ripening stages. ActaAgronomicaNigeriana, 9 (1\&2), 35- 40.

Dzhangaliev A.., Salova T. \&Turekhanova P. (2003). Pome fruits : In The wild fruit and nut plantas of Kazakhstan. J. Janick edition, pp311-324.

Gonsalves P. E. (2002). As frutas e seusbeneficios. FrutasQueCuram, 1: 131-166.

Hussain S., Masud T., Bano R., Wang H., Ali S. \& Ali A. (2015). Comparative study of two pear (Pyruscommunis L.) cultivars in terms of nutritional composition. Food Sci. \& Quality managemrnt, 36: 48-54.

Joubert P. M. \& Doty S. L. (2018). Endophytic yeasts: biology, ecology and applicatons. In endophytes of forest trees, forestry sciences, A. M. Pirttila\& A. C. Frand edition. Springer International Publishing, pp1-14.

Kaur R. \& Arya V. (2012). Ethnomedicinal and phytochemical persperctives of Pyruscommunis (L.). J. of Pharmacognosy and Phytochemistry, 1: 14-19.

Ladeji O., Akin C. U., \&Umaru H. A. (2005). Level of antinutritional factors in vegetables commonly eaten in Nigeria. African J. Nat. Sci., 71-73. 
Li X., Zhang J. Y., Gao W. Y., Wang Y., Wang H. Y., Cao J. G. \& Huang L. Q. (2012). Chemical composition and ant-inflammatory and antioxidant activities of eight pear cultivars. J. Agric \& Food Chem., 60(35): 8738-8744.

Magyar D., Shoemaker R. A., Bobvos J., Crous P. W. \&Groenewald J. Z. (2011). Pyrigemmula, a novel hypomycete genus on grapevine and tree bark. Mycol Progress, 10: 307-314.

Mahammed M. U., Kamba A. S., Abubakar L. \&Bagna E. A. (2010). Nutritional composition of pear fruits (Pyruscommunis). Afri. J. of Food Sci. \& Tech., 1(3): 76-81.

Milind P \&Arzoo (2016). Review: Why is pear so dear? Int. J. Res. Ayurveda Pharm., 7(1): 108113.

Muscat A., Sardella D., Decelis S., Gougouli M., Koatsoumanis K. P., Marin S. \&Valdramidis V. (2017). Fungal contamination of Pyruscommunis var. bambinella: macroscopic and molecular characterization. Bulletin of the Entomological Society of Malta, 9: 60-61.

Nnaji P. T. and Rao A. P. (2017). Fungal contamination of locally processed Nigerian food (okpa): A threat to public health. Journal of Advances in Microbiology, 4(1):1-8.

Olds R. J., (1983). A colour Atlas of Microbiology, $5^{\text {th }}$ edition, Wolf Medical Publication Ltd., London 213.

Orwa C., Mutua A., Kindt R., Jamnadass R. \& Simon A. (2009). Agroforestry database: a tree reference and selection guide version 4.0. http://www.worldagroforestry.org/af/treedb/.

Parveen S., Wani A., Bhat M. Y. \&Koka J. A. (2016). Biological control of post-harvest fungal rots of rosaceous fruit using microbial anagonists and plant extracts: A review. Czech Mycology, 68(1): 41-66.

Pugatenthi M., Vadivel V. \&Gurumoorthi P. (2005). Comparative nutritional evaluation of little known legumes,Tamarindusindica, Erythrima and Sesbaniabispinosa. Trop. Subtrop. Agroecosyst., 4:107-123.

Rychilnska I. \&Gudej J. (2003). Qualitative and auantitative chromatographic investigation of hydroquinone derivatives in Pyruscommunis L. flowers. ActaPolonicaPharmaceuticaDrug Res., 60:309-312.

Samson, R.J, Hoeskstra, E. S and Van Oorschot, C.A.N., (1981). Introduction to food borne fungi.Centraal bureau coorSchmmel cultures, Netherlands. 16 -170. Publisher Institute of Royal, Netherland.

Senser F., Scherz H. \&Muchen G. (1999). Tablasdecomposision de Alimentos, $2^{\text {nd }}$ edition. Editorial Acribia, Zaragoza.

Sharma K., Pasricha V., Satpathy G. \& Gupta R. K. (2015). Evaluation of phytochemical and antioxidant activity of raw Pyruscommunis (L.), an underexploited fruit. J. of Pharmacognosy and Phytochemistry, 3(5): 46-50. 
Silva G. J., Souza T. M., Barbieri R. L. \& de Oliveira A. C. (2014). Review: origin, domestication and dispersing of pear (Pyrus spp.). hindawi publishing corporation advances in agriculture, pp1-8. http://dx.doi.org/10.115/2014/541097.

Trigiano, R. N, Windham, M. J and Windham, A.S., (2004). Plant Pathology concept and Laboratory exercise. C.R.C. Press L.L.C, USA. 345-359.

USDA, (2012). National agricultural library, "National nutrient data-base for standard reference". http://ndb.nal.usda.gov/. retrieved $29^{\text {th }}$ June, 2019.

Vadivel V. \&Janardhanam K. (2005). The wonder of pears, free diets. Plant Food for Human Nutri., 60: 69-75.

Wenneker M., Pham K. T. K., Lemmers M. E. C., de Boer F. A., van Leeuwen P. J., Hollinger T. C., van de Geijn F. G. \&Thomma B. P. H. J. V. (2017). Fibulorhizoctoniapsychrophila is the causal agent of lenticel spot on apple and pear fruit in the Netherlands. Eur. J. of Plant Pathol., 148: 213-217.

Xie D., Zhong H., Mo J., Li Z., Cui T. \& Yi C. (2007). Nutritional and medicinal quality of pear juice: Next Hotspot? Food, 1(1): 41-48.

Yim S \& Nam S. (2016). Physiochemical nutritional and functional characterization of 10 different pear cultivars (Pyrus spp.). J. of Appl. Botany \& Food Quality, 89: 73-81.

Zhang Z. F. (2005). Study on chemical ingredients, juice proessing technology and volatile profile of Pyruspyrifolia. MSc. Thesis, Central South Forestry University, P. R. China. 